\title{
Leverage, beta estimation, and the size effect
}

\author{
Wolfgang Drobetz ${ }^{\mathrm{a}}$ and Jörg Seidel ${ }^{\mathrm{b}}$ \\ This version: January 2011
}

\begin{abstract}
This study shows that the size effect can be explained to a large extent by a measurement error in beta. The measurement error results from a change in financial leverage during the beta estimation window. Based on simulations of asset returns, we document that the size of the bias in equity returns is proportional to marketinduced changes in leverage, as suggested by Modigliani and Miller (1958). We propose a point-in-time beta that incorporates the leverage at the end of the beta estimation window rather than the average leverage during the estimation window. Using the point-in-time beta to compute expected returns for a sample of historical stock returns, we document that the size effect sharply decreases. In contrast to previous explanations of the size effect, our approach does not introduce market frictions or additional risk factors. It is consistent with the risk-return considerations in standard capital structure theory.
\end{abstract}

$\underline{\text { Keywords: }}$ Size effect, capital asset pricing model, capital structure, beta estimation.

\footnotetext{
${ }^{a}$ Wolfgang Drobetz, Institute of Finance, University of Hamburg, Von-Melle-Park 5, 20146 Hamburg, Germany. Mail: wolfgang.drobetz@wiso.uni-hamburg.de

${ }^{\mathrm{b}}$ Jörg Seidel, Institute of Finance, University of Hamburg, Von-Melle-Park 5, 20146 Hamburg, Germany. Mail: joerg@seidel.be
} 


\title{
Leverage, beta estimation, and the size effect
}

\author{
January 2011
}

\begin{abstract}
This study shows that the size effect can be explained to a large extent by a measurement error in beta. The measurement error results from a change in financial leverage during the beta estimation window. Based on simulations of asset returns, we document that the size of the bias in equity returns is proportional to market-induced changes in leverage, as suggested by Modigliani and Miller (1958). We propose a point-in-time beta that incorporates the leverage at the end of the beta estimation window rather than the average leverage during the estimation window. Using the point-in-time beta to compute expected returns for a sample of historical stock returns, we document that the size effect sharply decreases. In contrast to previous explanations of the size effect, our approach does not introduce market frictions or additional risk factors. It is consistent with the risk-return considerations in standard capital structure theory.
\end{abstract}

\section{Introduction}

The size effect, as originally reported in the empirical studies by Banz (1981) and Reinganum (1981), has been covered extensively in the asset pricing literature. The observation that small stocks outperform large stocks poses an "anomaly" of the Capital Asset Pricing Model (CAPM), apparently contradicting the notion that expected excess returns are solely explained by their covariance with the returns on the market portfolio. Fama and French (1992) and Fama and French (1993) also emphasize that neglecting the size effect, while relying on the CAPM's main prediction that differences in betas 
explain the cross-section of expected returns, may lead to substantial pricing errors in asset pricing tests.

Given that the true underlying beta is unobservable, most empirical tests of the CAPM rely on the estimation of single security betas or portfolios betas over a period of three to five years. These tests implicitely assume that the estimated beta is an unbiased predictor of the true beta. The previous literature describes possible biases in the estimated beta, ranging from data deficiencies (e.g., thin or asynchronous trading and survivorship biases) to stochastic effects. However, little research has focused on the bias that financial leverage introduces to beta estimation. The aim of this study is to close this gap.

We document using simulated returns for size-sorted portfolios that the estimated beta is a biased proxy for the point-in-time beta at the end of the beta estimation window. This measurement error in betas leads to biases in expected returns, and the bias is particularly pronounced for small firms. Accordingly, the size effect should not entirely be regarded a CAPM anomaly, but it is at least partly an artifact of the estimation technique used in virtually all empirical studies. The bias results from changes in financial leverage during the beta estimation window. Specifically, changing leverage leads to a downward bias in the estimated beta that is used to compute expected returns.

In the case of risk-free debt, the impact of financial leverage on a firm's equity beta is described by Modigliani and Miller's (1958) famous proposition II. Based on Hamada (1972), our analysis provides a correction for the bias in beta estimation. Adjusting the beta for changes in financial leverage during the beta estimation window, we are able to substantially reduce the size effect for both simulated and market data. The abnormal returns of small firms (many of which are past losers) become statistically insignificant in both cases. Overall, our study contributes to the literature in three ways. First, we provide evidence that the commonly used methodology for estimating beta creates a bias in expected returns for past losers. Second, we document that the size effect is attributable to measurement errors in betas. Finally, we suggest a simple correction for this bias and show that a point-in-time beta is able to substantially reduce the size effect.

There are a few earlier studies that are related to our analysis. Bhandari (1988) documents that leverage explains differences in cross-sectional returns even after correcting for size. However, he does not provide a model for why one should expect these differences and how big they should be. Moreover, he 
adds additional degrees of freedom to his regressions, which are not required in our simulation framework. Bhandari (1988) concludes that financial leverage should be an additional explanatory variable. Somewhat different, we do not argue that the debt-to-equity ratio is a proxy for risk that is independent from market risk. Instead, the change in leverage during the beta estimation window produces a biased proxy for the point-in-time beta at the end of the window. In other words, the "abnormal" returns are attributable to higher beta risk, which is induced by higher financial risk.

Ferguson and Shockley (2003) also report a bias in the estimated beta and a pricing error, which are a function of a firm's leverage. However, their argument is different from ours. They suggest that the bias stems from using an equity-only portfolio as a proxy for the true market portfolio. In our analysis, we observe a size effect even if the true market portfolio (at least as defined in our simulation setup) is used. Moreover, Ferguson and Shockley's (2003) correction of the bias requires adding new explanatory factors. Hecht (2002) investigates the size and book-to-market effects on asset returns and equity returns. He documents that both effects are only significant on the equity level (and not the firm level), and hence he concludes that they must be induced by leverage. Charoenrook (2004) confirms these findings using a larger sample. He further notes that any time-variation in the beta will cause an error-in-variables problem in the second pass of a Fama and MacBeth (1973) regression, but he does not investigate the magnitude of this bias.

Our study addresses the time-variation in beta and provides evidence for the effect of leverage on excepted returns. In contrast to Charoenrook (2004), we assume risk-free debt, and hence we need not rely on an appropriate specification of Merton's (1974) capital structure model. The specification of a pricing model for debt represents a potential error source because it requires to assume maturities and risk premiums. For example, Charoenrook (2004) assumes that the maturity of a firm's debt is the weighted average of all bonds outstanding. This assumption implies that debt never falls due (because average duration exceeds the maturity of the debt with the shortest maturity), and hence it neglects the risk of default for equity holders.

In order to demonstrate that the size effect shows up independent from any bias in the data sources, we choose a simulation approach. Our simulation framework is based on two fundamental assumptions: (1) the CAPM holds unconditionally for firms' asset returns, and (2) debt is risk-free. The first assumption allows isolating the effect of financial leverage on the timevariation of the equity beta. With a constant asset beta, any variation in the 
equity beta must be induced by leverage. The second assumption avoids the pricing of debt claims in a firm's capital structure. Any mispricing in debt would spill-over to equity returns, and hence any test becomes a joint-test of the effect of leverage on equity returns and the validity of the pricing model for debt.

Our results are complementary to Charoenrook's (2004) earlier findings. Without specifying a pricing model for debt, we nevertheless observe an effect of leverage on expected returns. Even more important, our simulation excludes a variety of alternative explanations, such as investor irrationality, thin or asynchronous trading, data quality, survivorship bias, choice of the wrong market portfolio, missing risk factor, premia for liquidity or estimation risk, higher moments or trading costs. Presumably, all these effects do affect equity returns, but they are not necessary to generate a size effect.

The remainder of this paper is organized as follows. Section 2 provides the necessary theoretical foundations. Section 3 describes our simulation framework, and section 4 presents our testable hypotheses. Section 5 discusses the simulation results, while section 6 applies our suggested correction for the point-in-time beta on U.S. stock market data. Finally, section 7 concludes and provides an outlook for future research.

\section{Theoretical foundations}

A variety of explanations have been suggested to explain the size effect. Financial leverage is put forward as one potential explanation. Most important, starting from Modigliani and Miller's (1958) proposition II, Hamada (1972) derives a relationship between a firm's leverage and its equity beta. Assuming risk free-debt, the equity beta, denoted as $\beta_{e}$, is just the levered version of the firm's asset beta, labeled $\beta_{A}$ :

$$
\beta_{e}=\beta_{A} \cdot\left(1+\frac{D}{E}\right)
$$

where $\frac{D}{E}$ is the debt-to-equity ratio. However, the relationship in equation (1) alone cannot explain the size effect because financial leverage should already be reflected in the estimated equity beta. Galai and Masulis (1976) develop an option pricing model that allows investigating the effects of the capital structure on a stock's systematic risk. They argue that a stock's 
systematic risk is the product of the firm's systematic risk and the price elasticity of the equity value with respect to changes in the firm's asset value. Based on Merton's (1974) model, the equity beta is not only a positive function of leverage, but also a negative function of the risk-free interest rate, the variance of the asset returns, and the time to maturity. Galai and Masulis (1976) derive the following generalized version of equation (1), relaxing the assumption of risk-free debt:

$$
\beta_{e}=\beta_{A} \cdot N\left(d_{1}\right) \cdot\left(1+\frac{D}{E}\right)
$$

DeJong and Collins (1985) use the Galai and Masulis (1976) framework to identify the sources of beta instability. In line with equation (2), they document that firms with higher leverage exhibit greater beta instability. They attribute higher residuals for high leverage firms in market model regressions to capital structure factors. However, they do not investigate the unbiasdness of the estimated beta. Using bond and equity data, Hecht (2002) analyses the cross-section of firms' asset returns. Compared to stock returns, he finds the patterns of book-to-market, reversal, and momentum effects to be less pronounced or non-existent in asset returns. He concludes that capital structure plays a major role in producing these effects. In a theoretical analysis, Charoenrook (2004) documents that Fama and MacBeth (1973) estimates are systematically biased in the presence of leverage. This bias is caused by the assumption that factor loadings are constant during the estimation period, and it leads to a relationship between expected stock returns and the book-to-market ratio and size, respectively.

Our paper adds to this strand of research by investigating the magnitude of the bias in the beta estimation that is caused by market-induced changes in leverage. We use a simulation approach with risk-free debt, as assumed in Hamada (1972) and described in equation (1). Simulating risky debt requires a pricing model for debt, and hence mispricing of debt would immediately cause mispricing of equity. We rather choose a simulation approach to create a clean-room sample that excludes many other explanations for the size effect, especially those pointing towards data deficiencies. For example, Roll (1981) argues that thin-trading causes the size effect. Thin-trading is clearly an observable effect in market data, but in our simulation setup no return is subject to thin or asynchronous trading. We also exclude any survivorship bias in our simulated returns (Kothari et al., 1995) and use the true market portfolio in the beta estimation (Roll and Ross, 1994; Ferguson and 
Shockley, 2003) to avoid possible mean-variance inefficiencies of the market portfolio proxy. No other risk factor can influence our results. For example, Amihud and Mendelson (1989) partly attribute the size effect to a liquidity premium, and the findings in Chan et al. (1985) point to a distress factor. Keim (1983) documents a relation of the size effect with the January effect. Klein and Bawa (1977) analyze the problem which investors face when the distribution of securities' returns has unknown parameters. In this case, estimation risk occurs, and hence investors will hold a portfolio that differs from the mean-variance optimum. Kraus and Litzenberger (1976) investigates investors' preference for higher moments of the return distribution. Finally, Berk (1995) argues that any missing risk factor will be proxied by firm size due to discounting effects. All these factors are excluded from our simulation framework, and hence they cannot drive our results. Our findings are also unaffected by data snooping (Black, 1993).

We model equity returns in the presence of financial leverage starting from asset returns based on a constant asset beta. In other words, we simulate equity returns for partly debt financed firms, assuming that the CAPM holds unconditionally for firms' asset returns. Even in this simplistic simulation setup, we observe a size effect as described in the prior literature. Therefore, we conclude that the size effect is caused endogenously within our simulation and identify the changes in leverage during the beta estimation window as the source of this bias. In a closely related paper, Choi (2009) uses market data and comes to similar conclusions based on the price elasticity of equity with respect to asset returns implied by equation (2). He also documents that the size and book-to-market effects are partly caused by financial leverage.

Moreover, we propose a simple correction for the bias in the estimated beta. The beta estimated over a 60 months time window, denoted as $\beta_{60}$, represents the average leverage, $L_{60}$, during the estimation period rather than the leverage at the end of the estimation window, $L_{t}$. Based on equation (1), we derive the asset beta, denoted as $\beta_{A}$, from dividing $\beta_{60}$ by $1+L_{60}$ for each decile portfolio. Assuming that the asset beta does not change during the estimation period, we use the leverage at the end of the estimation period to estimate a point-in-time equity beta, denoted as $\beta_{t}$ :

$$
\beta_{t}=\beta_{A} \cdot\left(1+L_{t}\right)=\beta_{60} \cdot \frac{\left(1+L_{t}\right)}{\left(1+L_{60}\right)}
$$

Correcting the estimated beta for leverage changes during the estimation window removes the size effect in simulated data and reduces it substantially 
using market data. However, both equation (1) and equation (2) are correct only in continuous time. Using these equations to compute point-in-time betas and to forecast discrete period returns leads to biased results because they implicitly assume that the equity beta is constant during the subsequent return measurement period. However, return-induced changes in leverage will similarly occur subsequent to the beta estimation window. Our findings indicate that this inaccuracy does not lead to a substantial bias as long as the return measurement period is short enough and the initial leverage is not too high. Nevertheless, even if the time interval is short but leverage is already very high, equation (3) will deliver excessively high point-in-time betas. In theory, one could mitigate this effect by applying equation (3) at any point in time a stock price is observable. However, too short intervals may lead to other problems, e.g., as poor return estimates due to thin trading.

\section{The simulation setup}

In our empirical framework, we simulate the market value of assets, denoted as $A_{i, t}$, for all firms $i(i=1, \ldots, N)$ with a given amount of debt, denoted as $D_{i, t}$. The market value of equity, labeled $E_{i, t}$, is the residual:

$$
E_{i, t}=A_{i, t}-D_{i, t}
$$

Given the simulated equity values, we are able to compute equity returns and to examine whether a size effect shows up in the simulated data. The proper choice of the processes for changes in $A_{i, t}$ and $D_{i, t}$ is essential. Specifically, the parameters must be chosen such that no size dependency is induced and that the Capital Asset Pricing Model (CAPM) holds for asset returns. As $E_{i, t}$ and $D_{i, t}$ are linearly dependent, any size dependency in the process for the market value of debt will spill over to the simulated equity values. For example, if debt returns increase with asset size, this leads to higher equity returns for smaller firms. However, this "size effect" is artificially caused by the process for the return on debt.

The goal of our simulation analysis is to demonstrate that the size effect is endogenous in the estimation of equity betas. In order to avoid any biases that result from the pricing model for debt, we choose the simplest possible setup: debt is assumed to be risk-free and of zero maturity. Accordingly, the market value of debt is equal to its face value at any time. Risk-free debt implies that a firm can be liquidated at no cost. As soon as the firm's asset 
value falls and becomes equal to the face value of debt, it will be liquidated immediately and its debt will be fully repaid. As debt has zero maturity, its value is also unaffected by changes in the risk-free interest rate. With debt being risk-free and of zero maturity, the market value of debt equals its face value at any point in time, and hence debt is always correctly priced.

Assuming risky debt or longer maturities requires an explicit model for the valuation of debt, and hence any model error potentially causes artificial effects in equity returns. Any empirical test becomes a joint hypothesis test of the patterns in equity returns and the model for the valuation of debt. For further simplification we assume that the risk-free interest rate is constant and zero. ${ }^{1}$

Asset returns follow a geometric Brownian motion with a continuously compounded expected rate of return and a continuously compounded variance. Although asset values are not directly observable, many standard models are based on this assumption (Merton, 1974). Our analysis indicates that financial leverage changes the moments of equity returns. The same is likely to be the case for asset returns in the presence of operating leverage, but our analysis is restricted to financial leverage. We assume that the CAPM holds unconditionally for asset returns. Accordingly, there is an unobserved market portfolio, and asset returns are proportional to their covariance with the returns on this market portfolio. By construction, the covariance with the market portfolio is the only source of expected returns. With a zero risk-free interest rate, the expected asset return for zero-beta firms is also equal to zero. Assuming that there is idiosyncratic volatility in asset returns, the correlation between the return on the market portfolio and asset returns is imperfect. Therefore, the instantaneous continuously compounded asset return for firm $i$ at time $t$, denoted as $\hat{r}_{a, t, i}$, is given as:

$$
\hat{r}_{A, t, i}=\underbrace{\sigma_{a} \cdot \epsilon_{i, t}-0.5 \cdot \sigma_{a}^{2}}_{\text {Idiosyncratic return }}+\underbrace{\gamma_{A, i} \cdot\left(\mu_{M}+\sigma_{M} \cdot \epsilon_{M, t}\right)}_{\text {Systematic return }} .
$$

The process in equation (5) consists of normally distributed firm-specific idiosyncratic returns, denoted as $\sigma_{a} \cdot \epsilon_{i, t}$, and normally distributed returns

\footnotetext{
${ }^{1}$ We run all simulations with time-varying risk-free interest rates using different stochastic processes. The results remain virtually unchanged. Intuitively, equity returns are increased by the amount of the risk-free rate, and in estimating beta we again subtract the risk-free rate and work with excess returns. Therefore, the interest rate cancels out, and its stochastic process has no influence on our main results.
} 
of the market portfolio, denoted as $\mu_{M}+\sigma_{M} \cdot \epsilon_{M, t} \cdot \gamma_{A, i}$ captures the linear dependency of asset returns from market returns similar to an asset beta. The term $-0.5 \cdot \sigma_{a}^{2}$ ensures that the expected discrete idiosyncratic return equals to zero. Therefore, in line with the CAPM, covariance with the market portfolio is the only source of expected asset returns.

We simulate instantaneous continuously compounded returns. Discrete returns cannot be normally distributed as assumed by the CAPM because the largest loss an investor can realize is $-100 \%$; however, the normal distribution supports the entire real line. In contrast, $\hat{r}_{A, t, i}$ is normally distributed due to its linear dependency on $\epsilon_{i, t}$ (which are firm-specific independent standard normal random numbers) and on $\epsilon_{M, t}$ (which are independent standard normal random numbers that capture innovations of the market portfolio). We set the parameter $\gamma_{A, i}$ equal to one for all firms, ensuring that any differences in the cross-section of equity returns are caused by differences in leverage and not by differences in asset betas.

Asset values are simulated over a period of time. Therefore, we need to define a continuously compounded asset return, labeled $r_{A,[t, t+1], i}$, which translates $\hat{r}_{A, t, i}$ into a return in finite time:

$$
r_{A,[t, t+1], i}=\left\{\begin{array}{l}
\hat{r}_{A, t+1, i}, \text { if } \forall t \in[t, t+1]: \hat{r}_{A, t, i}>\ln (D)-\ln (A) \\
\ln (D)-\ln (A) \text { otherwise. }
\end{array}\right.
$$

According to equation (6), $r_{A,[t, t+1], i}$ is equal to $\hat{r}_{A, t+1, i}$ if the asset value is greater than the value of debt during the entire time interval. However, if at any point during this time interval the firm's asset value drops to the value of debt, hence if the asset return is $\ln (D)-\ln (A)$, then $r_{A,[t, t+1], i}$ will also be equal to $\ln (D)-\ln (A)$. Equation (6) ensures that the continuously compounded asset return during an arbitrary time interval from $t$ to $t+1$, $r_{A,[t, t+1], i}$, is in line with our assumption of risk-free debt. If the check for liquidation was only made at the end of each period, asset values could potentially fall below the face value of debt. However, this loss incurred by lender contradicts our assumption that debt is risk-free.

In contrast to our simulation setup, with risky debt high equity returns would be derived if shareholders play a risk-shifting game at the expense of debtholder. While risk-shifting may potentially cause excessive equity returns if the market value of debt drops below the face value and asset values are being redistributed from debtholders to sharholders, our simulation results document that supposedly abnormal returns even occur in the absence 
of risk-shifting. Therefore, using the returns generated by equation (5) would dramatically increase the effect observed in our simulation. Another important property of our setup is that equation (6) does not add a trend to asset returns. If $\hat{r}$ has an expected value of zero, then $r_{A,[t, t+1], i}$ also shows an expected rate of return of zero independent of the choice of leverage.

Allowing for risky debt requires an explicit model to evaluate debt. The market value of debt would no longer be equal to its face value, and hence the return on debt would not be equal to the risk-free interest rate. Any return anomaly for equity returns could potentially be caused by errors in the model for the value of debt. Accordingly, our simulations would be a joint test of the size effect and the model for the value of debt. By allowing for immediate default (even within a given time interval), we ensure that debt is always correctly priced, and hence no pricing error in the valuation of debt can influence equity returns.

Our assumption of zero maturity debt is convenient from a mathematical point of view, but it also seems to be realistic from a practical standpoint. Most firms use current accounts and liquidity lines for their cash management. ${ }^{2}$ As soon as their asset value drops below the notional amount of total debt, their current account and any other access to the money market will dry up, and hence firms will default on lack of liquidity. This may even be the case in the presence of other tranches of debt with longer maturities. In fact, the time of default is likely to be triggered by debt with the shortest time to maturity, and in many instances this is daily revolving debt.

Unfortunately, our approach in equation (6) comes at a price. It implies that the distribution of asset returns needs to account for path dependency, as illustrated in figure 1 . In order to estimate the probability density of an asset value at the end of the period, $A_{i, t+1}$, we need to integrate of over all possible paths leading to this point from the starting value, $A_{i, t}$. We employ the path integral laid out by Feynman (1948). Because no solution to the path integral in equation (6) exists, we solve the problem numerically by slicing each period into 1,000 time slices and check for default at the end of each time slice. The high number of slices ensures that the pricing kernel is approximated with sufficient accuracy and that any remaining losses to debtholders are negligible compared to the observed effects in equity returns.

We use the continuously compounded return from equation $(6), r_{A,[t, t+1], i}$,

\footnotetext{
${ }^{2}$ According to Barclay and Smith (1995), firms with high leverage have a particularly high proportion of current debt.
} 


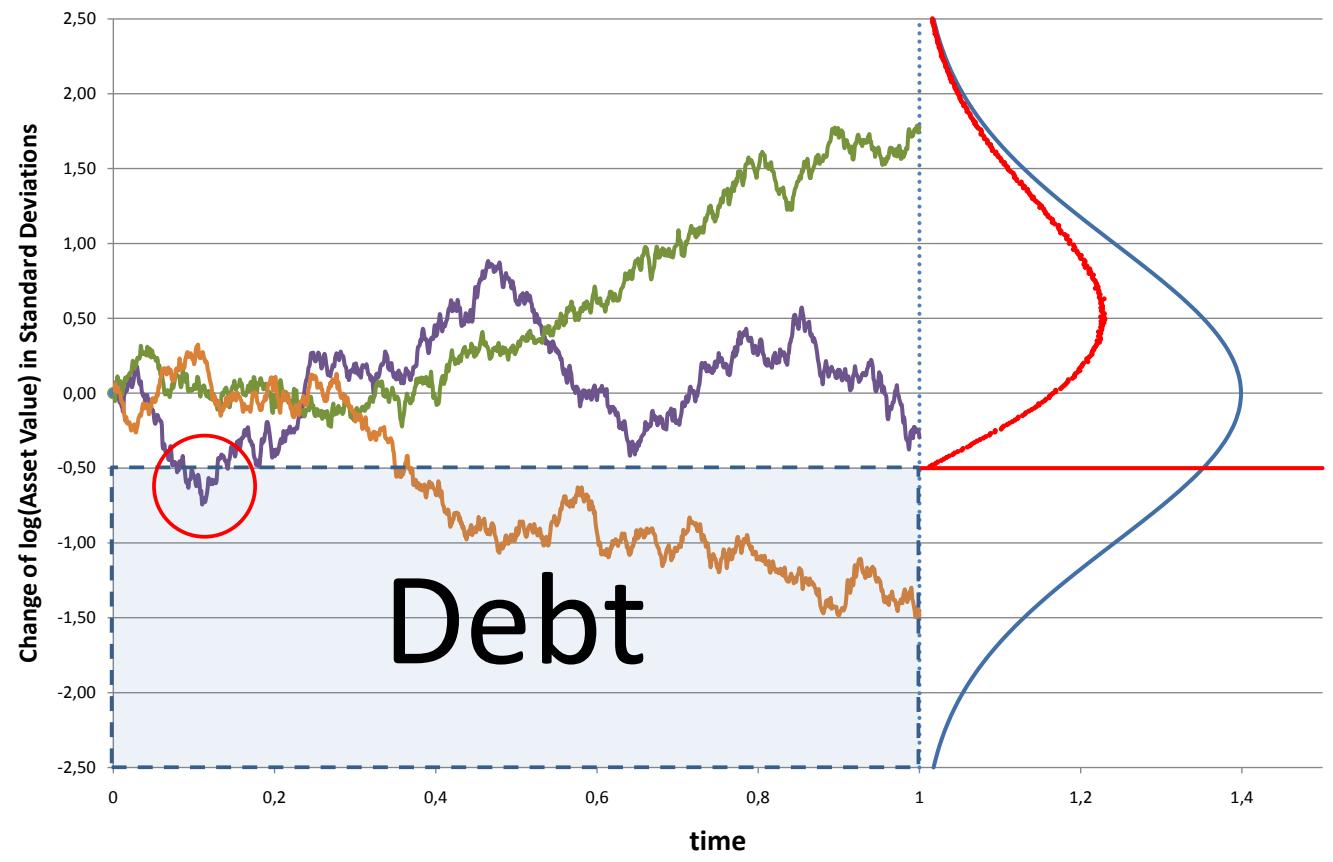

Figure 1: In the absence of debt, the distribution of $\log$ asset values at $t=1$ would be described by the blue normal distribution. However, for leveraged firms the distribution changes. The asset value cannot fall below the value of debt as this will lead to immediate liquidation. The red distribution takes this path dependency into account. There is a very high probability of a loss of -0.5 , expressed as the total market value of equity in units of standard deviation, because many simulation paths will fall below the debt level at least temporarily. The lilac path is above the debt level at $t=1$, but it will never reach this level as the firm will be liquidated at $t=0.1$, i.e., when it drops to the level of debt. For large positive returns the differences to the normal distribution are small and the distributions are asymptotically identical.

to calculate the change of asset values from time $t$ to $t+1$ as follows:

$$
A_{i, t+1}=A_{i, t} \cdot e^{r_{A,[t, t+1], i}} .
$$

Given that the expected asset return is positive, firms will either be liquidated if they reach the debt barrier, or they will grow large enough to render the level of debt negligible, hence avoiding the risk of default. Therefore, we need a rule to keep leverage in a plausible range and force the simulation to converge to a distribution with realistic debt ratios. Specifically, we assume that the simulated firms will pay a dividend if their leverage, labelled $L_{i, t}$ and measured as the firm's debt-to-equity ratio, falls below 0.5. ${ }^{3}$ This cash

\footnotetext{
${ }^{3}$ This model is clearly simplistic, but it suffices for our purpose. In reality, additional factors will influence the dividend payments, such as information asymmetry and agency problems.
} 
dividend subsequent to an increase in equity values will be financed by the issuance of new debt, and the amount to be issued and distributed is chosen such that leverage is exactly 0.5 after the dividend has been paid. The trigger level is set such that the resulting average leverage ratio for the largest size decile will approximately match the empirical leverage ratio in the largest size decile of US firms (which is approximately 0.652 according to Compustat Global Database). In order to increase the debt-to-equity ratio to the target leverage of 0.5 , the dividend, denoted as $d_{i, t}$, must be as follows:

$$
d_{i, t}=\max \left(0, \frac{A_{i, t}}{3}-D_{i, t}\right)
$$

The $\max (\cdot)$ function ensures that dividends are only paid if leverage falls below the target. ${ }^{4}$ The choice of the dividend payment does not strongly influence the results of our simulation because our primary interest is on high leverage firms (i.e., mainly small firms with negative past returns). These firms do not reach the lower trigger for leverage, and hence they do not distribute dividends. For debt-to-equity ratios above 0.5 all changes in leverage are induced by equity returns. The payment of dividends occurs at the end of each period $[t, t+1]$ during which the trigger level has been reached. Dividends are paid to shareholders and increase their total equity returns, denoted as $R_{e,[t, t+1], i}$. Because dividends are financed by debt, the level of debt is increased by the same amount, and hence we have:

$$
\begin{aligned}
R_{e,[t, t+1], i} & =\left(E_{t+1, i}+d_{i, t+1}-E_{t, i}\right) / E_{t, i} \\
D_{i, t+1} & =D_{i, t}+d_{i, t+1} \\
L_{i, t} & =\frac{D_{i, t}}{E_{i, t}}
\end{aligned}
$$

The novel idea of our simulation analysis is to show that there is an endogenous relationship between the market value of equity and the firm's leverage. In order to make sure that this size effect is really endogenous, we choose the starting values for the simulation such that there is no relationship between a firm's market value of equity and its leverage at the beginning of

\footnotetext{
${ }^{4}$ To see that this simple rule implements the desired target leverage, assume that $D=2$, $E=10$, and hence $A=12$. According to equation (8), the dividend is $\frac{A}{3}-D=4-2=2$. After the dividend has been paid out, $D=2+2=4, E=10-2=8$, and $L=\frac{4}{8}=0.5$.
} 
the simulation. Therefore, we have:

$$
\begin{aligned}
E_{i, 0} & =\nu \cdot 10, \\
L_{i, 0} & =\nu \cdot 2, \\
D_{i, 0} & =E_{i, 0}, \cdot L_{i, 0}, \\
A_{i, 0} & =D_{i}+E_{i, 0} .
\end{aligned}
$$

In order to generate dispersion in leverage ratios, $\nu$ denotes equally distributed random numbers in the interval from zero to one. By drawing the random variates for the starting values of equity, $E_{i, 0}$, independently from the starting values of leverage, $L_{i, 0}$, we ensure that there is no correlation between these two firm characteristics at the start of the simulation, and hence any size effect must be endogenous. By choosing the values for equity and leverage, we also determine the starting values for debt, $D_{i, 0}$, and total assets, $A_{i, 0}$.

Finally, we construct the return on the market portfolio, labelled $R_{m, t}$, as the cross-sectional value-weighted average of all simulated equity returns. Ferguson and Shockley (2003) argue that using an equity-only proxy for the market portfolio may cause a size bias in the estimated equity betas if the firms' equity returns covary with the omitted assets from the market portfolio. However, this problem should not be important in our simulation setup because equities are the only return-generating securities. The return on the market portfolio is given as:

$$
R_{m, t}=\frac{\sum_{i=1}^{N} R_{e, t, i} \cdot E_{t-1, i}}{\sum_{i=1}^{N} E_{t-1, i}}
$$

Based on the framework described in this section, we are able to simulate a set of firms with specific asset returns, debt-to-equity ratios, and equity returns. It allows us to examine whether the size effect shows up in this very general distribution of equity returns and is inherent in the underlying return structure.

\section{Testable hypotheses}

We use simulated equity values and equity returns to examine whether the size effect shows up in our clean room sample. Following Reinganum (1981), 
in each month $t$ we sort firms into size deciles according to their simulated market value of equity, $E_{i, t}$. Firms with an equity value of zero in period $t$ are marked as defaulted; they are not further considered in this and all later periods. However, in period $t$ they are assigned a return $R_{e, t, i}=-100 \%$ to avoid a survivorship bias. For each size decile we form an equally-weighted portfolio. Using portfolio returns over the period from $t-60$ to $t$, we estimate portfolio betas, denoted as $\beta_{60}$, against the simulated market returns, $R_{m, t}$. We also record the subsequent portfolio returns over the period $t$ to $t+1$.

Portfolios are formed in each simulation month $t$, and the average return and average beta are computed for each decile over time. As there is no size specific factor in our simulations, we expect that each size portfolio has the same average beta and exhibits the same average return. Accordingly, we formulate the first two testable hypotheses:

Hypothesis H1: The average estimated betas of all size portfolios are equal.

Hypothesis H2: The average estimated returns of all size portfolios are equal.

In case hypotheses 1 and 2 do not hold, and given that the CAPM holds for asset returns by construction, we expect that any cross-sectional variation in returns can be explained by variation in betas. This leads to an alternative testable hypothesis:

Hypothesis H2.a: There is a linear relationship between average estimated portfolio returns an average estimated betas.

Equation (13) ensures that leverage is independent of the market value of equity across firms at the start of our simulations. The market value of equity changes, and hence leverage also changes along each simulation path. Therefore, we test if the average leverage is still equal across all size deciles:

Hypothesis H3: The average leverage is equal across all size deciles.

As Modigliani and Miller (1958) point out, we should expect higher equity returns for firms with higher leverage (financial leverage). If hypothesis 2.a does not hold, we expect that leverage (at least partly) explains the deviation from the linear relationship between average estimated returns and average estimated betas. 


\section{Simulation results}

We run our simulations for $N=20,000$ firms, and each firm's asset returns are simulated for $T=500$ months. Firms are simulated using an idiosyncratic monthly asset return volatility of $\sigma_{a}=0.045$, a volatility of the market portfolio of $\sigma_{M}=0.0085$, and an expected return of the market portfolio of $\mu_{M}=0.0034$. The numbers are chosen to generate equity returns that are comparable to those in the sample of U.S. firms (see section 6). However, our main simulation results are not limited to this particular set of parameters, and the findings with different sets of parameters are qualitatively similar.

Table 1 presents the first five moments of all simulated return series. The continuously compounded asset returns are close to a normal distribution, despite the asymmetry introduced by equation (6). The number of periods with firm liquidations is too small relative to the overall sample, and hence the effect on the shape of the distribution is not strongly pronounced. Nevertheless, the deviation in skewness $(0.138)$ is caused by path dependency in equation (6). They disappear if the simulation is performed without debt.

\begin{tabular}{rrrrrr} 
Moment & $r_{A, t, i}$ & $R_{e, t, i}$ & $r_{e, t, i}$ & $R_{M, t}$ & $r_{M, t}$ \\
\hline \hline 1 & 0.004 & 0.008 & 0.003 & 0.007 & 0.006 \\
2 & 1.000 & 1.000 & 1.000 & 1.000 & 1.000 \\
3 & 0.138 & 0.454 & -0.054 & -0.172 & -0.212 \\
4 & 3.018 & 8.703 & 4.667 & 2.847 & 2.892 \\
5 & 1.376 & 46.781 & -1.012 & -2.090 & -2.492 \\
\hline
\end{tabular}

Table 1: The table shows the first five moments of the simulated time series. The moments are presented as averages across all firms. They are normalized such that the standard deviation is always equal to one, which simplifies a comparison of the shape of the distributions. $r_{A, t, i}$ are the continuously compounded asset returns, while $R_{e, t, i}$ and $R_{m, t}$ are the discrete equity and market returns, respectively. $r_{e, t, i}$ and $r_{m, t}$ are the continuously compounded equity and market returns, respectively, which are calculated as $r=\log (1+R)$. For the moment calculation all infinite equity returns are removed from the sample.

The effect is different for continuously compounded equity returns. They exhibit an increased kurtosis of 4.667 (instead of 3, which is implied by a normal distribution). However, there is little asymmetry in the simulated returns. Both skewness and the fifth moment are close to zero. The signs of the uneven moments become negative, while they are positive for asset returns in the presence of leverage. Equation (6) introduces a positive skew to asset returns; they can grow unlimited but have a floor at $\ln (D)-\ln (A)$ on the downside. In contrast, for continuously compounded equity returns there is no floor on the downside, as an asset return of $\ln (D)-\ln (A)$ implies 
an equity return of $-\infty$. While the probability of an ever increasing return converges to zero, the probability of a return of $-\infty$ is larger than zero and finite. Although we remove all infinite returns from the sample for the purpose of moment calculation, the remaining effect is strong enough to reverse the positive skewness in asset returns. Without debt all returns are normally distributed, and hence we conclude that the skewness in returns is a function of a firm's leverage. Transformed into discrete returns the skewness (0.454) and the fifth moment (46.781) of equity returns are positive because the loss is limited on the downside.

In order to test our hypotheses laid out in section 4, we sort firms into ten portfolios according to their size (as measured by the market value of equity) into deciles portfolios in each month. For each decile portfolio and for each month we estimate the beta, denoted as $\beta_{60}$, using the market returns in the 60 months prior to the formation month. The resulting values are shown in the Table 2 and visualized in Figure 2.

On average, each decile portfolio consists of about 1,580 firms. The estimated beta, $\beta_{60}$, ranges from 0.959 for the firms with the highest market value of equity (decile 10) to 1.384 for the firms with the lowest market value of equity (decile 1). This difference in betas is significant (based on a $t$-test for differences in means), and hence we have to reject hypothesis 1 , suggesting that the estimated betas are equal for all deciles. Although we exclude any size dependency in our simulation setup, there is a clear relationship between firm size and estimated betas. Moreover, we also reject hypothesis 2 that returns are equal for all decile portfolios. The annualized returns range from 0.629 for large cap stocks to 0.155 for small cap stocks. Again, this difference is statistically significant.

We compute expected excess returns, denoted as $E\left(R_{e}\right)$, by multiplying estimated betas, $\beta_{60}$, with the average excess return of the market portfolio, $E\left(R_{m}\right)$. The simulation results in Table 2 reveal that the relationship between the average realized (simulated) equity return, $R_{e}$, and the average expected equity return, $E\left(R_{e}\right)=\beta_{60} \times E\left(R_{m}\right)$, is non-linear. The pricing error, labeled $P E\left(\beta_{60}\right)$ and defined as $R_{e}-E\left(R_{e}\right)$, is relatively small for large cap stocks; it is less than $0.03 \%$ per month for each of the top eight decile portfolios. However, the first two decile portfolios have a large pricing error of $0.250 \%$ and $0.094 \%$ per month. Both these pricing errors are larger than zero, with $t$-values indicating statistical significance at the $1 \%$ level. Accordingly, our simulation produces return patterns that are in line with real world data. Most important, there is a clear relationship between size, beta, and 


\begin{tabular}{rrrrrrrrrrrr} 
Decile & $R_{e}$ & $\beta_{60}$ & $\beta_{t}$ & $\beta_{A}$ & $\emptyset L E V_{60}$ & $\emptyset L E V_{t}$ & $\emptyset E_{60}$ & $\emptyset E_{t}$ & PE $\beta_{60}$ & PE $\beta_{t}$ & ADR \\
\hline \hline 1 & 1.155 & 1.384 & 1.812 & 0.582 & 1.376 & 2.111 & 1.13 & 0.83 & 0.250 & -0.029 & 0.536 \\
& $(0.06)$ & $(0.03)$ & & & $(0.05)$ & $(0.03)$ & $(0.14)$ & $(0.01)$ & $(4.28)$ & $(-0.50)$ & $(0.02)$ \\
2 & 0.925 & 1.271 & 1.365 & 0.577 & 1.204 & 1.367 & 3.14 & 2.64 & 0.094 & 0.033 & 0.034 \\
& $(0.03)$ & $(0.02)$ & & & $(0.05)$ & $(0.01)$ & $(0.42)$ & $(0.05)$ & $(2.97)$ & $(1.03)$ & $(0.00)$ \\
3 & 0.808 & 1.196 & 1.221 & 0.577 & 1.074 & 1.117 & 5.15 & 4.69 & 0.026 & 0.010 & 0.004 \\
& $(0.02)$ & $(0.02)$ & & & $(0.05)$ & $(0.01)$ & $(0.71)$ & $(0.09)$ & $(1.23)$ & $(0.46)$ & $(0.00)$ \\
4 & 0.751 & 1.142 & 1.138 & 0.578 & 0.976 & 0.970 & 7.35 & 7.07 & 0.004 & 0.006 & 0.001 \\
& $(0.02)$ & $(0.02)$ & & & $(0.05)$ & $(0.01)$ & $(1.07)$ & $(0.13)$ & $(0.27)$ & $(0.41)$ & $(0.00)$ \\
5 & 0.709 & 1.095 & 1.078 & 0.576 & 0.902 & 0.872 & 9.94 & 9.94 & -0.007 & 0.004 & 0.000 \\
& $(0.01)$ & $(0.01)$ & & & $(0.04)$ & $(0.01)$ & $(1.53)$ & $(0.20)$ & $(-0.57)$ & $(0.34)$ & $(0.00)$ \\
6 & 0.720 & 1.059 & 1.034 & 0.575 & 0.840 & 0.797 & 13.15 & 13.57 & 0.028 & 0.044 & 0.000 \\
& $(0.01)$ & $(0.01)$ & & & $(0.04)$ & $(0.00)$ & $(2.14)$ & $(0.28)$ & $(2.39)$ & $(3.77)$ & $(0.00)$ \\
7 & 0.671 & 1.035 & 1.006 & 0.579 & 0.787 & 0.738 & 17.27 & 18.38 & -0.006 & 0.013 & 0.000 \\
& $(0.01)$ & $(0.01)$ & & & $(0.03)$ & $(0.00)$ & $(2.97)$ & $(0.40)$ & $(-0.58)$ & $(1.35)$ & $(0.00)$ \\
8 & 0.646 & 1.021 & 0.990 & 0.586 & 0.743 & 0.690 & 23.14 & 25.37 & -0.022 & -0.001 & 0.000 \\
& $(0.01)$ & $(0.01)$ & & & $(0.03)$ & $(0.00)$ & $(4.24)$ & $(0.58)$ & $(-2.40)$ & $(-0.15)$ & $(0.00)$ \\
9 & 0.628 & 0.989 & 0.957 & 0.582 & 0.698 & 0.643 & 33.17 & 37.66 & -0.019 & 0.002 & 0.000 \\
& $(0.01)$ & $(0.01)$ & & & $(0.03)$ & $(0.00)$ & $(6.67)$ & $(0.94)$ & $(-2.31)$ & $(0.26)$ & $(0.00)$ \\
10 & 0.629 & 0.959 & 0.930 & 0.586 & 0.637 & 0.587 & 69.69 & 85.08 & 0.002 & 0.021 & 0.000 \\
& $(0.01)$ & $(0.01)$ & & & $(0.03)$ & $(0.00)$ & $(17.09)$ & $(2.59)$ & $(0.28)$ & $(2.80)$ & $(0.00)$ \\
\hline
\end{tabular}

Table 2: The table summarizes the simulation results for the ten size portfolios. Decile 1 contains the firms with the smallest market value of equity, and decile 10 contains the firms with the largest market value of equity. $R_{e}$ is the average discrete excess equity return over the risk-free interest rate. Returns are multiplied by 100. $\beta_{60}$ denotes the beta estimated using the returns from the prior 60 months. $\beta_{t}$ is the average point-in-time beta estimated according to equation (3), and $\beta_{A}$ is the corresponding asset beta. $\emptyset L E V_{60}\left(\emptyset E_{60}\right)$ is the average leverage (equity value) during the beta estimation period, and $\emptyset L E V_{t}\left(\emptyset E_{t}\right)$ is the average leverage (equity value) at the end of the beta estimation period. The columns labeled PE contain the average pricing errors based on the different beta estimates. Pricing errors are multiplied by 100. ADR denotes the average "default" rate, hence the percentage of firms with an equity return of less than $-90 \%$. For the pricing error columns the numbers in brackets are t-values for the hypothesis that the error equals zero. All other numbers in brackets are standard errors.

stock returns. The returns of small cap stocks are too high to be explained by the differences in betas, and hence we observe a CAPM "anomaly" in the smallest size deciles. While excess returns are high for the smallest firms, the pricing error is only small for the larger firms.

Table 2 further indicates that in the bottom half of the decile portfolios containing small cap stocks the average market capitalization at the end of the beta estimation period, denoted as $\emptyset E_{t}$, is smaller than the average firm capitalization within the beta estimation period, labeled $\emptyset E_{60}$. For the top half of the decile portfolios containing large cap stocks the relationship is the other way round; on average, the size at the end of the estimation period is larger than within the period. This implies that sorting firms by market capitalization implicitly sorts firms by past returns. Presumably, small firms have a higher probability of having suffered from prior negative returns, and large firms have a higher probability of having experienced prior positive 
returns.

In our simulations firms pay a dividend if leverage falls below 0.5. Firms with positive returns and hence lower leverage can counterbalance the marketinduced changes in leverage by paying a higher dividend. In contrast, small cap stocks cannot react to changes in market leverage. Consistent with the empirical evidence for price run-ups prior to equity issuances (Baker and Wurgler, 2002; Chang and Dasgupta, 2009), our simulation setup prevents firms from raising fresh equity to compensate past losses. This effect results in increasing leverage for past losers and, violating hypothesis 3 , in a correlation between leverage and firm size. Table 2 indicates higher leverages for small cap stocks than for large cap stocks. Both the average leverage during the estimation period, denoted as $\emptyset L E V_{60}$, and the average leverage at the end of the estimation period, labeled $\emptyset L E V_{t}$, are decreasing with increasing size deciles. It is important to note that our setup does not impose any correlation. By construction, at the start of our simulations the average leverage is equal across all size deciles.

Our findings are in line with recent empirical results. Welch (2004) documents that changes of a firm's market value are primarily responsible for changes in market leverage. Accordingly, a firm with negative past returns tends to be smaller and exhibits, on average, higher leverage than firms with positive past returns. Welch (2004) points out that managers in his U.S. sample seem to do little in the short-run to counterbalance these marketinduced changes in leverage. Bessler et al. (2008) report similar results for European firms. They also show that managers do little to rebalance leverage in the short-run and even tend to exacerbate market-induced changes by issuing stocks after stock price increases, apparently in an attempt to time the market.

Given that small cap stocks, on average, suffer from a negative performance during the estimation period for $\beta_{60}$, their market capitalization at the end of the estimation period is smaller than the market capitalization at the beginning of the estimation period and the period average market capitalization. Another implication is that leverage at the end of the estimation period is higher than the period average leverage. Modigliani and Miller (1958) establish a direct link between leverage, financial risk, and expected returns. While $\beta_{60}$ is estimated over all 60 time intervals and reflects the risk of the average leverage during the estimation window, the expected return in the next period is proportional to the firm's leverage at the end of the estimation window. A problem does not occur as long the average leverage is a 
good proxy for the period-end leverage. However, Table 2 indicates that this proxy becomes increasingly bad for the small decile portfolios. As a result, the estmated beta becomes less accurate for these small capitalization portfolios and suffers from a downward bias. In fact, for the smallest decile the average leverage in the estimation period is only about $65 \%$ of the leverage at the end of the period, which is (at least partly) responsible for the size effect.
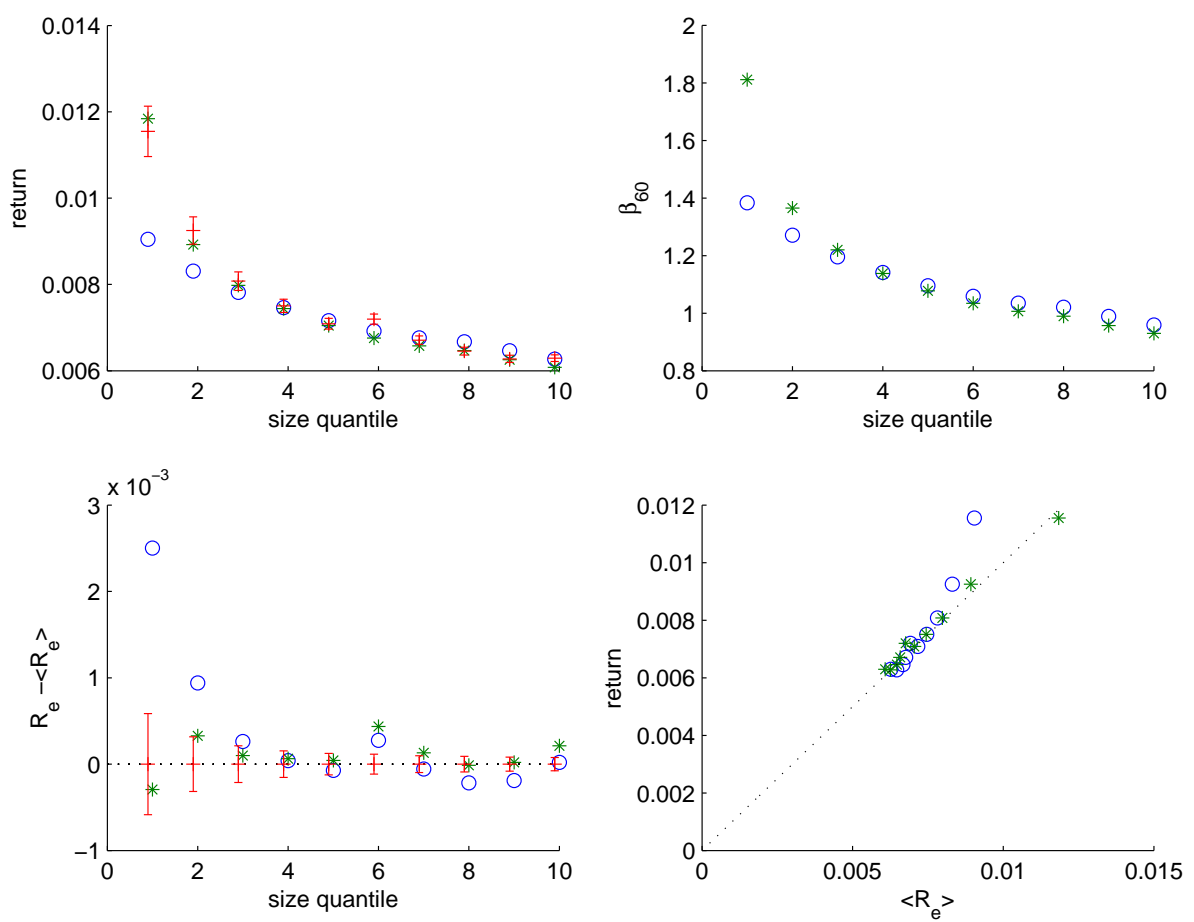

Figure 2: The figure visualizes the simulation results for size decile portfolios. Decile 1 contains the firms with the smallest market value of equity, and decile 10 contains the firms with the largest market value of equity. The blue circles depict the results based on $\beta_{60}$, the green asterisks those using the leverage correction, and the red crosses are the measured returns. For measured returns the error bars indicate the confidence interval of plus and minus one standard error. The top left graph plots size deciles against measured and expected returns, and the top right graph plots size deciles agains estimated betas. In the bottom right graph measured returns are plotted against expected returns based on the estimated betas. Finally, the bottom left graph depicts pricing errors across size deciles.

Neverthless, past market returns are not solely responsible for the correlation between size and leverage. In fact, even within a given size decile leverage impacts beta estimation and pricing errors. Specifically, we split the 
smallest size decile portfolio into ten subdecile portfolios according to their market value of equity as shown in Table 3. Even within this subsample of bad performing stocks the size effect is still observable, and equity returns decrease with size. Again, the size effect is most pronounced in the smallest two subdeciles. Both portfolios exhibit a high excess return of roughly $1.4 \%$ per month, which is more than 0.4 percentage points higher than expected based on the estimated $\beta_{60}$. This observation is in line with the findings by Fama and French (2007) that the size effect is caused by the migration of extremely small firms (microcaps) with extremely high returns. Knez and Ready (1997) also document that the size effect is caused by a few extreme observations.

\begin{tabular}{rrrrrrrrrrrrr} 
Decile & $R_{e}$ & $\beta_{60}$ & $\beta_{t}$ & $\beta_{A}$ & $\emptyset L E V_{60}$ & $\emptyset L E V_{t}$ & $\emptyset E_{60}$ & $\emptyset E_{t}$ & PE $\beta_{60}$ & PE $\beta_{t}$ & ADR \\
\hline \hline 1 & 1.400 & 1.462 & 2.727 & 0.583 & 1.509 & 3.679 & 0.16 & 0.08 & 0.444 & -0.383 & 1.723 \\
& $(0.15)$ & $(0.05)$ & & & $(0.07)$ & $(0.22)$ & $(0.02)$ & $(0.00)$ & $(2.95)$ & $(-2.54)$ & $(0.06)$ \\
2 & 1.383 & 1.409 & 2.056 & 0.573 & 1.462 & 2.590 & 0.42 & 0.24 & 0.462 & 0.040 & 1.090 \\
& $(0.11)$ & $(0.05)$ & & & $(0.06)$ & $(0.03)$ & $(0.06)$ & $(0.00)$ & $(4.04)$ & $(0.35)$ & $(0.05)$ \\
3 & 1.314 & 1.414 & 1.906 & 0.583 & 1.423 & 2.266 & 0.63 & 0.40 & 0.390 & 0.068 & 0.723 \\
& $(0.10)$ & $(0.05)$ & & & $(0.05)$ & $(0.03)$ & $(0.08)$ & $(0.01)$ & $(3.78)$ & $(0.66)$ & $(0.04)$ \\
4 & 1.075 & 1.411 & 1.823 & 0.592 & 1.385 & 2.081 & 0.84 & 0.56 & 0.153 & -0.116 & 0.542 \\
& $(0.10)$ & $(0.05)$ & & & $(0.06)$ & $(0.03)$ & $(0.10)$ & $(0.01)$ & $(1.58)$ & $(-1.19)$ & $(0.03)$ \\
5 & 1.061 & 1.387 & 1.720 & 0.586 & 1.368 & 1.937 & 1.04 & 0.73 & 0.155 & -0.063 & 0.364 \\
& $(0.08)$ & $(0.04)$ & & & $(0.05)$ & $(0.02)$ & $(0.12)$ & $(0.01)$ & $(1.86)$ & $(-0.75)$ & $(0.03)$ \\
6 & 1.044 & 1.365 & 1.649 & 0.579 & 1.357 & 1.846 & 1.23 & 0.89 & 0.151 & -0.034 & 0.282 \\
& $(0.07)$ & $(0.04)$ & & & $(0.06)$ & $(0.02)$ & $(0.15)$ & $(0.02)$ & $(2.04)$ & $(-0.46)$ & $(0.02)$ \\
7 & 0.974 & 1.358 & 1.613 & 0.579 & 1.346 & 1.787 & 1.45 & 1.07 & 0.087 & -0.080 & 0.225 \\
& $(0.07)$ & $(0.04)$ & & & $(0.06)$ & $(0.02)$ & $(0.18)$ & $(0.02)$ & $(1.17)$ & $(-1.09)$ & $(0.02)$ \\
8 & 1.046 & 1.353 & 1.577 & 0.583 & 1.322 & 1.706 & 1.65 & 1.25 & 0.162 & 0.015 & 0.168 \\
& $(0.07)$ & $(0.04)$ & & & $(0.06)$ & $(0.02)$ & $(0.21)$ & $(0.02)$ & $(2.24)$ & $(0.21)$ & $(0.02)$ \\
9 & 1.019 & 1.346 & 1.540 & 0.583 & 1.307 & 1.641 & 1.86 & 1.42 & 0.139 & 0.012 & 0.147 \\
& $(0.06)$ & $(0.04)$ & & & $(0.05)$ & $(0.02)$ & $(0.24)$ & $(0.02)$ & $(2.20)$ & $(0.19)$ & $(0.02)$ \\
10 & 1.006 & 1.333 & 1.501 & 0.583 & 1.285 & 1.573 & 2.05 & 1.61 & 0.135 & 0.025 & 0.095 \\
& $(0.06)$ & $(0.04)$ & & & $(0.05)$ & $(0.02)$ & $(0.27)$ & $(0.03)$ & $(2.18)$ & $(0.40)$ & $(0.01)$ \\
\hline
\end{tabular}

Table 3: The table summarizes the simulation results when the smallest size decile (microcap firms) in Table 2 is further split into ten subdeciles. Decile 1 contains the microcap firms with the smallest market value of equity, and decile 10 contains the microcap firms with the largest market value of equity. $R_{e}$ is the average discrete excess equity return over the risk-free interest rate. Returns are multiplied by 100 . $\beta_{60}$ denotes the beta estimated using the returns from the prior 60 months. $\beta_{t}$ is the average point-in-time beta estimated according to equation (3), and $\beta_{A}$ is the corresponding asset beta. $\emptyset L E V_{60}\left(\emptyset E_{60}\right)$ is the average leverage (equity value) during the beta estimation period, and $\emptyset L E V_{t}\left(\emptyset E_{t}\right)$ is the average leverage (equity value) at the end of the beta estimation period. The columns labeled PE contain the average pricing errors based on the different beta estimates. Pricing errors are multiplied by 100. ADR denotes the average "default" rate, hence the percentage of firms with an equity return of less than $-90 \%$. For the pricing error columns the numbers in brackets are t-values for the hypothesis that the error equals zero. All other numbers in brackets are standard errors.

Looking at the smallest subdecile portfolios, the spread Table 3 between the leverage at the end of the period and the average leverage within the 
period is even larger than in Table 2, which causes an even more pronounced size effect. The estimated $\beta_{60}$ is not able to explain the cross-section of returns across subdeciles. As visualized in Figure 3, there is almost no relationship between $\beta_{60}$ and stock returns. While excess returns increase from $1.001 \%$ to $1.400 \%$ per month, the betas increase only slighlty from 1.333 to 1.462 .
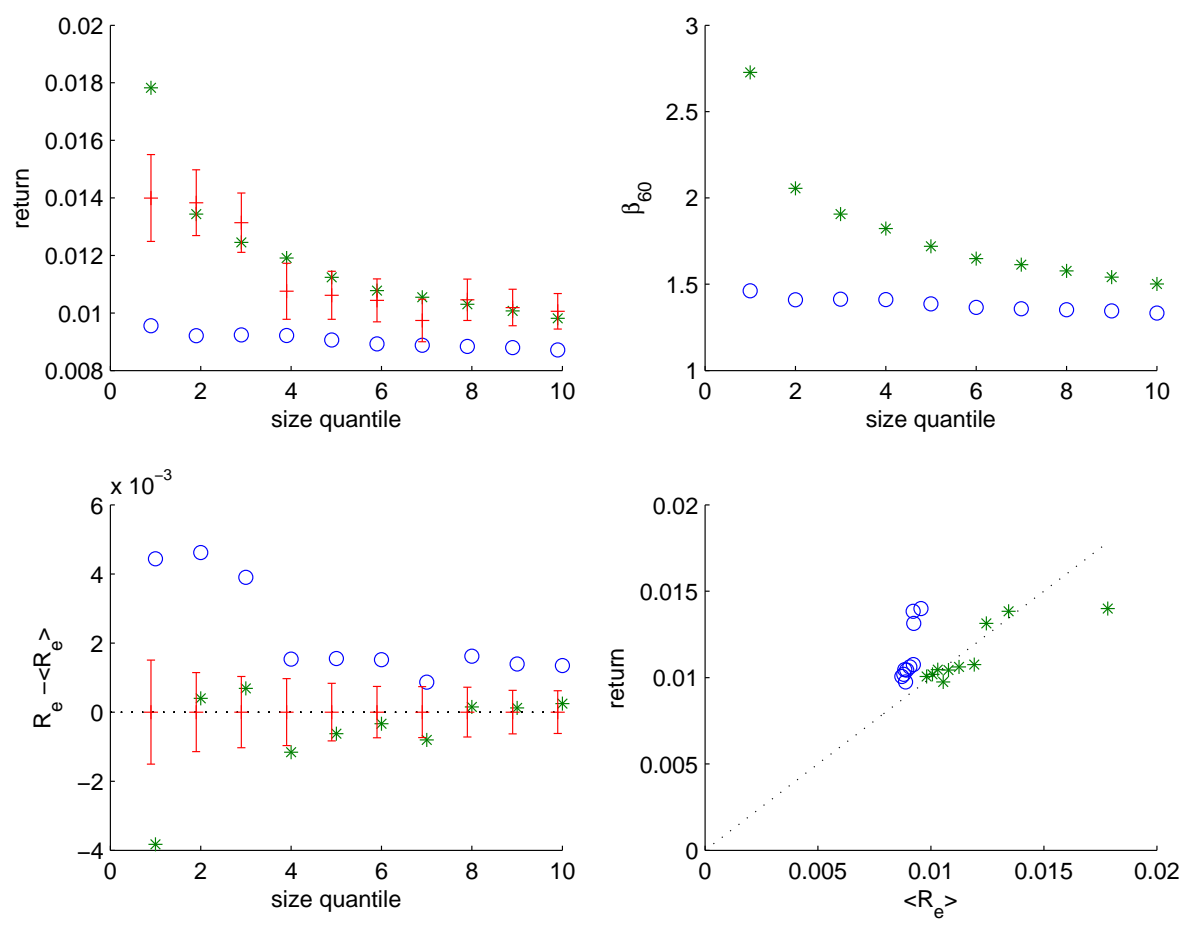

Figure 3: The figure visualizes the simulation results when the smallest size decile (microcap firms) in Table 2 is further split into ten subdeciles. Decile 1 contains the microcap firms with the smallest market value of equity, and decile 10 contains the microcap firms with the largest market value of equity. The blue circles depict the results based on $\beta_{60}$, the green asterisks those using the leverage correction, and the red crosses are the measured returns. For measured returns the error bars indicate the confidence interval of plus and minus one standard error. The four quadrants are organized as in Figure (3).

The spread between $L E V_{60}$ and $L E V_{t}$ could be reduced by choosing a shorter estimation period for betas. However, there is a trade-off, as a shorter estimation period will also lead to greater estimation errors in the market model regressions. We propose a more convenient solution to reduce pricing errors. By applying equation (3), we correct the estimated beta for the spread between $L E V_{60}$ and $L E V_{t}$, thereby enhancing estimation accuracy by 
accounting for the leverage at the end of the period. Table 2 and Figure 2 report the simulation results using our proposed correction of endogenous leverage changes during the beta estimation window. While the estimated betas are in line with the traditional betas for large firms, there are considerable deviations for small cap stocks. The estimated point-in-time betas, denoted as $\beta_{t}$, lie well above the estimated coefficients $\beta_{60}$ for the two smallest decile portfolios, implying that the traditional beta estimation method causes a downward bias for these portfolios. In our simulation setup, this downward bias fully explains the size anomaly. Using the point-in-time betas corrects the bias, and the abnormal returns for the small decile portoflios disappear. In fact, the pricing error, labeled $P E\left(\beta_{t}\right)$, becomes relatively small even for the two smalles decile portfolios. If the size effect is attributable to a misestimation of beta, the higher returns for small cap stocks come with higher beta risk. This finding also implies that an investment strategy based on the size effect will not produce any risk-adjusted outperformance.

A caveat with our method for beta correction is the assumption that the asset beta is constant during the estimation period. Moreover, many firms will also work with operating leverage for which, in principle, the same arguments can be made. ${ }^{5}$ Firms with large fixed costs and small variable costs, and hence high operating leverage, will suffer losses in adverse market conditions. Lower sales will further increase the ratio between fixed costs and variable costs, thereby increasing operating leverage. Again, one would expect that firms with negative prior asset returns will have a higher asset beta at the end of the estimation period than within the estimation period. Our correction does not account for this effect, and hence we may still underestimate the equity beta even after correcting for changes in financial leverage. In our simulation framework we keep the asset beta constant over time. Nevertheless, even for market data we suggest that correcting for changes in financial leverage during beta estimation period will lead to more precise beta estimates than without any such correction.

The effect of our correction is even more pronounced for the subdeciles of the smallest portfolios, as shown in Figure 3. For these very small firms (microcaps) the standard beta has little explanatory power, while the pointin-time beta still tracks the observed returns. An exception is the smallest subdecile, where the expected return based on the point-in-time beta is higher

\footnotetext{
${ }^{5}$ See Lev (1974) for the relationship between operating leverage and risk. Mandelker and Rhee (1984) report a correlation between financial and operating leverage.
} 
than the measured return. We do not have an explanation for this apparent overestimation. However, one reason could be that both equation (1) and equation (2) are correct only in continuous time. Using them to forecast discrete period returns again leads to biased results because it implicitly assumes that the equity beta in equation (2) remains constant during the return measurment period subsequent to the beta estimation window. Our simulation indicates that this inaccuracy does not lead to a significant bias in the case of risk-free debt as long the time period is short enough and the level of leverage is not too high. For the already highly leveraged firms, however, the point-in-time beta will not be constant during the period for which we estimate expected equity returns. If the firm does not default, its equity value sharply increases, the level of leverage decreases, and hence equation (3) will deliver an overestimated point-in-time betas for the smallest firms.

In the prior literature many explanations for the size effect have been proposed. Our approcah is novel in that it does not introduce any frictions to the CAPM such as trading costs, liquidity constraints, or irrational investors. We also omit adding new risk factors, and hence covariance with the market portfolio is the only source of return. Indeed, we did not add any new fitting parameters to align ex-ante and ex-post returns. Accordingly, we show that even in a frictionless mean-variance setup (in which the CAPM holds by definition), one should expect to observe a size effect if the beta is measured over a longer time window and hence does not reflect the point-intime leverage of the firm.

Based on our simulation results, we suggest that any beta estimation needs to correct for leverage changes during the estimation window, and this is especially necessary if the beta of small stocks is estimated. Nevertheless, this effect need not to be, or even is unlikely to be, the only size-related factor that effects returns. In reality, there are frictions such as liquidity constraints, trading costs, information cost, estimation risk, and many other factors that may affect the return the marginal investor requires to hold a small firm in diversified porfolios. Our findings merely indicate that none of these frictions are necessary for a size effect to show up given the standard beta estimation method.

Our findings also have major implications for empirical corporate finance research. Any test of a firm's risk adjusted long-run performance after some financing event simultaneously tests the validity of the expected return model (bad-model problem; Fama (1998)). Given that the average beta is a biased estimate for the point-in-time beta, using this average beta will in itself pro- 
duce biased results. However, even using the point-in-time beta would not be accurate in long-run performance studies because the expected point-intime beta will change itself after the event due to return-induced changes in leverage. For example, if an event study identifies two subsamples of positive and negative post-event returns, the average beta of the positive return subsample will drop over time, whereas the average beta of the negative return susample will increase over time. In standard event study methodology, the benchmark fails to incorporate these changes, which in turn leads to biased abnormal return estimates.

In addition, whenever a firm actively changes its capital structure, ceteris paribus, its point-in-time beta also changes. Analyzing capital structure changes in an event-study framework, e.g., the effect of share repurchases on subsequent stock returns, without adjusting the estimated betas appro-

priately will lead to biased results. For example, investigating the effect of share repurchases without adjusting for the resulting leverage increase, one would expect that the estimated betas are biased downwards. The bias will be more pronounced for firms that experience prior negative performance. For example, Ikenberry et al. (1995) document high abnormal returns for value stocks and neutral performance for growth stocks after the repurchase. They attribute this effect to undervaluation prior to the event. While their notion may be perfectly true, we argue that part of the effect they observe is attributable to a leverage-induced mismeasurement in betas.

\section{Empirical results}

In order to test our proposed method for beta correction with market data, our sample consists of all U.S. firm that are covered in the Compustat Global database within December 1988 to December 2007. Total return data and market values are taken from Thomson Datastream, and hence we need to exclude all firms without stock market data in this database. We also exclude financial and utility firms because they differ in leverage from other firms. In total, 2,932 firms remain in our sample. Total liabilities from Compustat Global are taken as our proxy for debt.

Our sample contains some firms that suffer from thin trading. To address this issue, we use monthly returns and also exclude all firm months in which the firm has an equity return of zero or a market value of equity of less than USD 1 million at the beginning of the period. Ince and Porter (2006) report 
data quality problems in the Thompson Datastream return data, and hence we make all the corrections they suggest. This data cleaning step leads to a removal of 363 firm-months from our sample. Overall, the remaining sample consists of 447,019 firm-months.

Table 4 provides a data description. As in the simulated returns, the average moments of the discrete equity returns, $R_{e, i, t}$, are all positive. However, the historical returns are more skewed. The odd moments become negative for continuously compounded returns, and the effect is more pronounced for historical returns. A potential explanation is that the empirical leverage is somewhat higher than in our simulation framework.

\begin{tabular}{rrrrr} 
Moment & $R_{e, t, i}$ & $r_{e, t, i}$ & $R_{M, t}$ & $r_{M, t}$ \\
\hline \hline 1 & 0.024 & -0.001 & 0.010 & 0.009 \\
2 & 1.000 & 1.000 & 1.000 & 1.000 \\
3 & 1.064 & -0.216 & -0.493 & -0.641 \\
4 & 10.321 & 6.869 & 3.572 & 3.851 \\
5 & 60.335 & -9.309 & -5.064 & -6.975 \\
\hline
\end{tabular}

Table 4: The table shows the first five moments of our U.S. sample. The moments are presented as averages across all firms. They are normalized such that the standard deviation is always equal to one, which simplifies a comparison of the shape of the distributions. $r_{A, t, i}$ are the continuously compounded asset returns, while $R_{e, t, i}$ and $R_{m, t}$ are the discrete equity and market returns, respectively. $r_{e, t, i}$ and $r_{m, t}$ are the continuously compounded equity and market returns, respectively, which are calculated as $r=\log (1+R)$. For the moment calculation all infinite equity returns are removed from the sample.

The moments of the market portfolios constructed from U.S. equity returns differs from the moments of our simulated market portfolio. In our simulation the returns of the market portfolio are close to a normal distribution for both discrete and continuous time returns. For the U.S. sample this is only true for the even moments, whereas the odd moments have negative loadings. In particular, a skewness of -0.493 represents a substantial deviation from normality. Again, this might be induced by somewhat higher leverage in the U.S. sample than in our simulated sample.

We again sort all firms into size decile portfolios, and the results are shown in Table 5 and in Figure 4. As in our simulations, for the smallest (largest) five decile portfolios the equity value is smaller (larger) at the end of the beta estimation window than during this window. Moreover, the results reveal two effects that are related to leverage. First, there is a clear negative correlation between size and leverage. Firms in the smallest decile portfolio have an average debt-to-equity ratio of 5.709, while firms in the largest decile portfolio have an average debt-to-equity ratio of 0.780 during 
the beta estimation window. However, this correlation between size and leverage is not enough by itself to conclude that there is a misestimation in beta; any increase in covariance with market returns due to higher leverage should already be reflected in the estimated beta. Second, for firms in the smallest decile portfolios their leverage at the end of the estimation window is, on average, higher than during the estimation window. In decile 1 the difference is even more than a factor of two. Ceteris paribus, we expect that this effect leads to an underestimation of the true point-in time beta if the beta is determined based on the prior 60 months window.

\begin{tabular}{rrrrrrrrrrrr} 
Decile & $R_{e}$ & $\beta_{60}$ & $\beta_{t}$ & $\beta_{A}$ & $\emptyset L E V_{60}$ & $\emptyset L E V_{t}$ & $\emptyset E_{60}$ & $\emptyset E_{t}$ & PE $\beta_{60}$ & PE $\beta_{t}$ & ADR \\
\hline \hline 1 & 2.783 & 1.077 & 2.360 & 0.160 & 5.709 & 13.706 & 60.28 & 18.32 & 2.050 & 1.177 & 0.038 \\
& $(0.58)$ & $(0.22)$ & & & $(2.51)$ & $(1.03)$ & $(31.36)$ & $(0.61)$ & $(3.57)$ & $(2.05)$ & $(0.01)$ \\
2 & 1.575 & 1.219 & 1.499 & 0.399 & 2.059 & 2.761 & 127.24 & 64.53 & 0.745 & 0.555 & 0.017 \\
& $(0.41)$ & $(0.18)$ & & & $(0.61)$ & $(0.14)$ & $(48.90)$ & $(2.35)$ & $(1.80)$ & $(1.34)$ & $(0.01)$ \\
3 & 1.467 & 1.302 & 1.323 & 0.526 & 1.478 & 1.517 & 198.02 & 132.24 & 0.581 & 0.567 & 0.010 \\
& $(0.39)$ & $(0.16)$ & & & $(0.38)$ & $(0.05)$ & $(70.00)$ & $(5.01)$ & $(1.48)$ & $(1.45)$ & $(0.01)$ \\
4 & 1.159 & 1.216 & 1.146 & 0.555 & 1.190 & 1.065 & 264.01 & 224.87 & 0.332 & 0.379 & 0.003 \\
& $(0.37)$ & $(0.12)$ & & & $(0.28)$ & $(0.03)$ & $(77.26)$ & $(8.38)$ & $(0.89)$ & $(1.02)$ & $(0.00)$ \\
5 & 0.903 & 1.177 & 1.045 & 0.540 & 1.181 & 0.937 & 371.23 & 350.92 & 0.102 & 0.192 & 0.003 \\
& $(0.34)$ & $(0.12)$ & & & $(0.33)$ & $(0.02)$ & $(109.32)$ & $(12.85)$ & $(0.30)$ & $(0.57)$ & $(0.00)$ \\
6 & 0.615 & 1.191 & 1.106 & 0.601 & 0.983 & 0.842 & 519.45 & 533.71 & -0.195 & -0.138 & 0.003 \\
& $(0.31)$ & $(0.09)$ & & & $(0.22)$ & $(0.02)$ & $(143.21)$ & $(19.07)$ & $(-0.63)$ & $(-0.44)$ & $(0.00)$ \\
7 & 0.437 & 1.157 & 1.119 & 0.626 & 0.847 & 0.786 & 751.13 & 837.83 & -0.350 & -0.324 & 0.000 \\
& $(0.28)$ & $(0.07)$ & & & $(0.10)$ & $(0.01)$ & $(186.89)$ & $(28.61)$ & $(-1.23)$ & $(-1.14)$ & $(0.00)$ \\
8 & 0.198 & 1.143 & 1.090 & 0.618 & 0.849 & 0.763 & 1231.43 & 1427.93 & -0.579 & -0.543 & 0.000 \\
& $(0.23)$ & $(0.07)$ & & & $(0.07)$ & $(0.01)$ & $(296.30)$ & $(45.81)$ & $(-2.48)$ & $(-2.32)$ & $(0.00)$ \\
9 & 0.334 & 1.127 & 1.058 & 0.626 & 0.800 & 0.691 & 2628.08 & 3128.26 & -0.433 & -0.386 & 0.003 \\
& $(0.19)$ & $(0.06)$ & & & $(0.07)$ & $(0.01)$ & $(609.34)$ & $(93.78)$ & $(-2.32)$ & $(-2.07)$ & $(0.00)$ \\
10 & 0.456 & 1.006 & 0.934 & 0.565 & 0.780 & 0.652 & 20565.97 & 25737.31 & -0.228 & -0.179 & 0.000 \\
& $(0.08)$ & $(0.07)$ & & & $(0.09)$ & $(0.01)$ & $(5331.43)$ & $(687.55)$ & $(-2.92)$ & $(-2.29)$ & $(0.00)$ \\
\hline
\end{tabular}

Table 5: The table summarizes the results for the ten size portfolios based on U.S. market data. Decile 1 contains the firms with the smallest market value of equity, and decile 10 contains the firms with the largest market value of equity. $R_{e}$ is the average discrete excess equity return over the risk-free interest rate. Returns are multiplied by 100 . $\beta_{60}$ denotes the beta estimated using the returns from the prior 60 months. $\beta_{t}$ is the average point-in-time beta estimated according to equation (3), and $\beta_{A}$ is the corresponding asset beta. $\emptyset L E V_{60}\left(\emptyset E_{60}\right)$ is the average leverage (equity value) during the beta estimation period, and $\emptyset L E V_{t}$ $\left(\emptyset E_{t}\right)$ is the average leverage (equity value) at the end of the beta estimation period. The values for $E_{60}$ and $E_{t}$ are in USD millions. The columns labeled PE contain the average pricing errors based on the different beta estimates. Pricing errors are multiplied by 100. ADR denotes the average "default" rate, hence the percentage of firms with an equity return of less than $-90 \%$. For the pricing error columns the numbers in brackets are t-values for the hypothesis that the error equals zero. All other numbers in brackets are standard errors.

The debt-to-equity ratio in the smallest portfolio (in decile 1) of U.S. firms is 13.7 , which is much higher than the debt-to-equity ratio of 2.4 of the smallest portfolio in our simulation. Presumably, an explanation is our assumption of risk-free debt. High leverage increases the liquidation risk in our 
simulation setup because instantaneous liquidation actually takes place. In reality, creditors will face a loss even on current accounts if the firm defaults, and hence liquidation takes place at some later stage, which in turn produces even higher levels of leverage. However, the debt-to-equity ratio shown in Table 5 is not the real market leverage because we only use the accounting value of total liabilities as a proxy for the market value of debt. For firms that have experienced prolonged negative asset returns, the true market value of debt may be smaller due to default risk, and hence the leverage values that are based on accounting debt will be biased upwards. Despite high leverage, default rates are low if we define a monthly equity return of $-90 \%$ or less as default. Even in the smallest decile the average default rate, denoted as ADR, is only $0.038 \%$, which potentially indicates a survivorship bias in our sample which is an intersection of the Compustat Global and Datastream Thomson databases.

Table 5 further indicates that the estimated average beta, $\beta_{60}$, does not vary as much across the size deciles as the leverage. The beta is higher for small cap stocks, but the difference compared to large cap stocks is below $30 \%$ even in the best case and much much smaller than the differences in leverage, which increases by a factor of seven. This could partly be caused by a residual thin trading bias in the beta estimation. Although we use monthly returns and exclude months with a return of zero, residual thin trading is likely to persist. This will lead to a downward bias in the beta estimates especially for the smallest decile portfolio. In fact, the estimated betas in deciles one and two are even smaller than in decile 3 despite an increasing leverage, indicating a downward bias in these extreme deciles.

The results also shows a relationship between size and return. The return in the smallest portfolio (decile 1) is more than four times larger than in the largest portfolio (decile 10). This number should be interpreted with care because the sample probably suffers from a survivorship bias. Our sample is created as an intersection of the Compustat Global and Datastream Thomson databases. Any missing data in either of the two sources will be missing in our sample, implying a combined bias that is even greater than the bias in each data source separately. Nevertheless, the size effect is much more pronounced than in our simulation, which we attribute partly to the higher debt-to-equity ratios in the U.S. sample.

Table 4 also shows the results when we apply our proposed beta correction. The average asset betas estimated using equation (1) are very similar in the narrow range between 0.526 and 0.626 for the largest $80 \%$ of firms. 

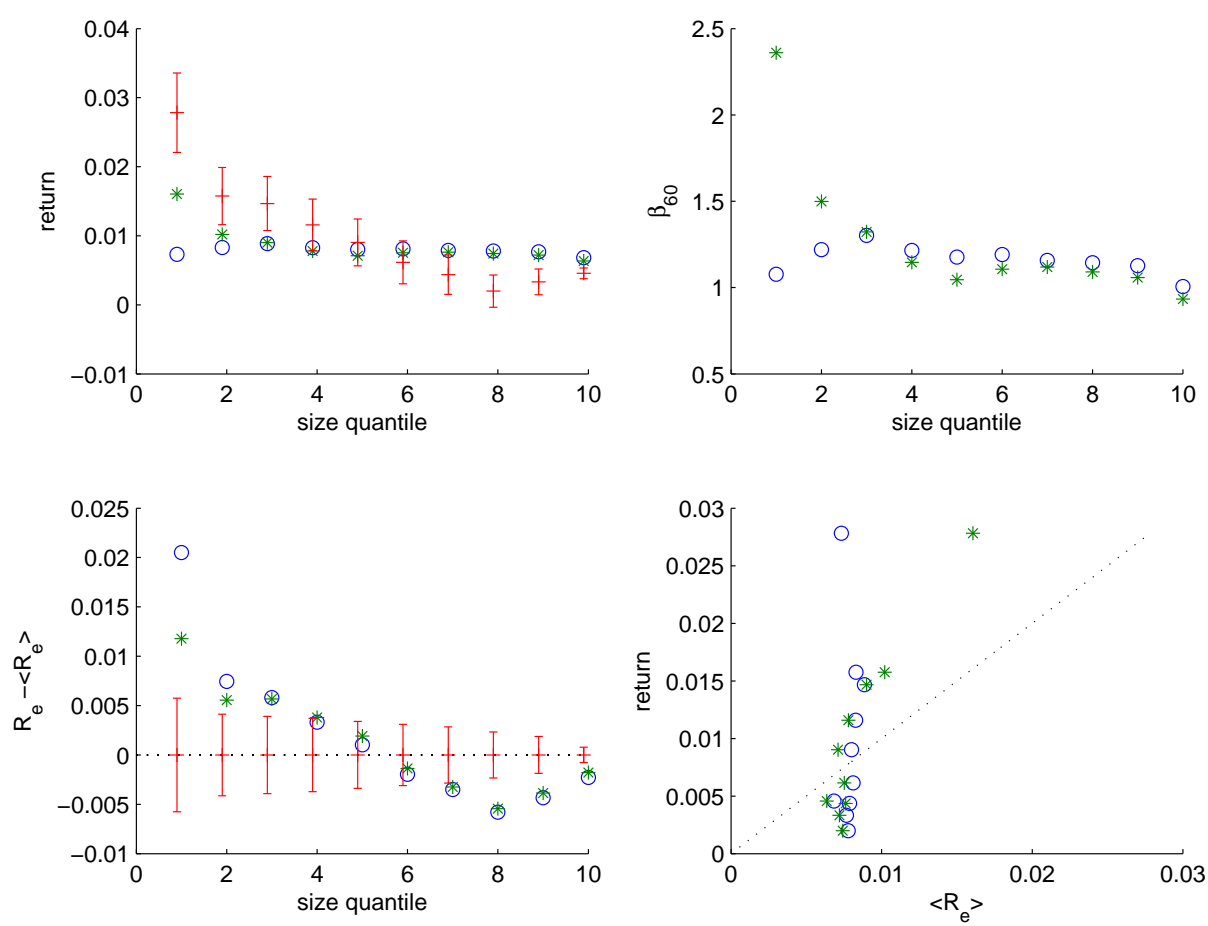

Figure 4: The figure visualizes the simulation results for historical U.S. size decile portfolios. Decile 1 contains the firms with the smallest market value of equity, and decile 10 contains the firms with the largest market value of equity. The blue circles are the results based on $\beta_{60}$, the green asterisk are the results using the leverage correction, and the red crosses are the measured returns. For measured returns the error bars indicate the confidence interval of plus and minus one standard error. The top left graph plots size deciles against measured and expected returns, and the top right graph plots size deciles agains estimated betas. In the bottom right graph ex-post returns are plotted against expected returns based on the estimated betas. Finally, the bottom left graph depicts pricing errors across size deciles.

However, the asset betas are substantially lower for the smallest two decile portfolios with only 0.399 and 0.160 , respectively. This potentially indicates that the betas of small firms are estimated too low, e.g., due to a thin-trading bias. Releveraging asset betas using equation (3) delivers substantially higher point-in-time betas, $\beta_{t}$, for small cap stocks compared to the corresponding $\beta_{60}$ estimates. Similar to our simulation results, $\beta_{60}$ exhibits a downward bias as a proxy for the true beta at the end of the estimation window. Correcting for this bias reduces the risk-adjusted "size effect". While the pricing error for small cap stocks is $2.05 \%$ per month if $\beta_{60}$ is used to calculate the expected return, it reduces to $1.18 \%$ after the correction. The corresponding 
$t$-value drops from 3.57 to 2.05 , implying a lower significance level of only 95\% compared to $99.9 \%$. Overall, our empirical findings indicate that the size premium is substantially lower when beta is corrected for the market-induced changes in leverage. This implies that the high returns of small stocks are at least partly the result from higher financial risk that investors take over.

\section{Conclusions}

Using simulation analyses, we document that even in a frictionless world a size effect exists for portfolios of firms grouped by the market value of equity. This effect is caused by market-induced changes in leverage during the beta estimation window, which makes the estimated beta a biased proxy for the true point-in-time beta at the end of the estimation window. Firms that have suffered from low equity returns during the beta estimation window exhibit, on average, higher leverage at the end of the estimation window than within. Accordingly, a measurement error occurs because this higher leverage is not reflected in the estimated beta; in particular, the estimated beta is biased downwards for small firms. Using this beta to estimate riskadjusted returns will in turn lead to seemingly unexplained excess returns and pricing errors. We suggest a simple correction for this beta measurement error, which eliminates the size effect in simulated returns and greatly reduces it in historical returns for a sample of U.S. firms.

Our setup is very general, and our correction for the bias in estimated betas potentially explains many other CAPM anomalies. Another attractive feature of our approach is that we do not need to introduce frictions or additional risk drivers to the CAPM, and hence it requires fewer assumptions than previous explanations for CAPM anomalies. Finally, our findings have implications for long-term events studies, as they are especially prone to measurement errors in expected returns. This is even more the case if the event triggers a change in capital structure. For example, not correcting for the increase in leverage induced by a share repurchase will underestimate expected returns, and hence it leads to the possibly wrong conclusion that firms that buy back shares subsequently experience higher risk-adjusted returns. As another example, consider an investor who wants to pay a fund manager only for his value-added rather than for the risk he takes. The investor needs to make sure that the risk measure reflects the point-in-time systematic risk rather the risk experienced in the past. Fund managers could try to exploit 
this effect and invest in firms that have experienced an increase in leverage during the contractually agreed beta estimation window.

\section{References}

Amihud, Y. and Mendelson, H. (1989). The effects of beta, bid-ask spread, residual risk, and size on stock returns. Journal of Finance, 44(2):479-486.

Baker, M. and Wurgler, J. (2002). Market timing and capital structure. Journal of Finance, 57(1):1-32.

Banz, R. W. (1981). The relationship between return and market value of common stocks. Journal of Financial Economics, 9(1):3-18.

Barclay, M. and Smith, C. (1995). The Maturity Structure of Corporate Debt. Journal of Finance, 50(2):609-631.

Berk, J. (1995). A critique of size-related anomalies. Review of Financial Studies, 8(2):275-286.

Bessler, W., Drobetz, W., and Pensa, P. (2008). Do managers adjust the capital structure to market value changes? Evidence from Europe. Zeitschrift für Betriebswirtschaft, (6):113-145.

Bhandari, L. (1988). Debt/equity ratio and expected common stock returns: Empirical evidence. Journal of Finance, 43(2):507-528.

Black, F. (1993). Beta and Return: Anouncements of "death" of beta seem premature. Journal of Portfolio Management, 20:8-18.

Chan, K. C., Chen, N.-f., and Hsieh, D. A. (1985). An exploratory investigation of the firm size effect. Journal of Financial Economics, 14(3):451-471.

Chang, X. and Dasgupta, S. (2009). Target behavior and financing: How conclusive is the evidence. Journal of Finance, 64:1767-1996.

Charoenrook, A. (2004). The Role of Capital Structure in Cross-sectional Tests of Equity Returns. Working Paper.

Choi, J. (2009). Rethinking the Conditional CAPM: The Impact of Financial Leverage. Working Paper. 
DeJong, D. and Collins, D. W. (1985). Explanations for the instability of equity beta: Risk-free rate changes and leverage effects. Journal of Financial and Quantitative Analysis, 20(1):73-94.

Fama, E. (1998). Market efficiency, long-term returns, and behavioral finance. Journal of Financial Economics, 49(3):283-306.

Fama, E. F. and French, K. R. (1992). The cross-section of expected stock returns. Journal of Finance, 47(2):427-465.

Fama, E. F. and French, K. R. (1993). Common risk factors in the returns on stocks and bonds. Journal of Financial Economics, 33(1):3-56.

Fama, E. F. and French, K. R. (2007). Migration. Financial Analysts Journal, $63(3): 48-58$.

Fama, E. F. and MacBeth, J. D. (1973). Risk, return, and equilibrium: Empirical tests. Journal of Political Economy, 81(3):607-636.

Ferguson, M. and Shockley, R. (2003). Equilibrium "Anomalies". Journal of Finance, 58(6):2549-2580.

Feynman, R. (1948). Space-time approach to non-relativistic quantum mechanics. Reviews of Modern Physics, 20(2):367-387.

Galai, D. and Masulis, R. W. (1976). The option pricing model and the risk factor of stock. Journal of Financial Economics, 3(1/2):53-81.

Hamada, R. (1972). The Effect of the Firm's Capital Structure on the Systematic Risk of Common Stocks. Journal of Finance, 27(2):435-452.

Hecht, P. A. (2002). The Cross Section of Expected Firm (Not Equity) Returns. SSRN eLibrary, Harvard Business School Working Paper Series:03044 .

Ikenberry, D., Lakonishok, J., and Vermaelen, T. (1995). Market underreaction to open market share repurchases. Journal of Financial Economics, $39(2-3): 181-208$.

Ince, O. and Porter, R. (2006). Individual Equity Return Data from Thomson Datastream: Handle with Care! Journal of Financial Research, 29(4):463479. 
Keim, D. B. (1983). Size-related anomalies and stock return seasonality : Further empirical evidence. Journal of Financial Economics, 12(1):13-32.

Klein, R. and Bawa, V. (1977). The effect of limited information and estimation risk on optimal portfolio diversification. Journal of Financial Economics, 5(1):89-111.

Knez, P. and Ready, M. (1997). On the Robustness of Size and Book-toMarket in Cross-Sectional Regressions. Journal of Finance, 52(4):13551382 .

Kothari, S., Shanken, J., and Sloan, R. (1995). Another look at the crosssection of expected stock returns. Journal of Finance, 50(1):185-224.

Kraus, A. and Litzenberger, R. (1976). Skewness preference and the valuation of risk assets. Journal of Finance, 31(4):1085-1100.

Lev, B. (1974). On the Association between Operating Leverage and Risk. Journal of Financial and Quantitative Analysis, 9(04):627-641.

Mandelker, G. and Rhee, S. (1984). The Impact of the Degrees of Operating and Financial Leverage on Systematic Risk of Common Stock. Journal of Financial and Quantitative Analysis, 19(01):45-57.

Merton, R. (1974). On the pricing of corporate debt: The risk structure of interest rates. Journal of Finance, 29(2):449-470.

Modigliani, F. and Miller, M. (1958). The Cost of Capital, Corporation Finance and the Theory of Investment. American Economic Review, 48(3):261-297.

Reinganum, M. (1981). Misspecification of capital asset pricing. Journal of Financial Economics, 9(1):19-46.

Roll, R. (1981). A Possible Explanation of the Small Firm Effect. Journal of Finance, 36(4):879-888.

Roll, R. and Ross, S. (1994). On the Cross-Sectional Relation between Expected Returns and Betas. Journal of Finance, 49(1):101-121.

Welch, I. (2004). Capital structure and stock returns. Journal of Political Economy, 112(1):106-131. 